\title{
Assessment of the relationship between mandibular molars and inferior alveolar nerve-diagnostic significance and accuracy of panoramic radiography
}

\author{
Rossen Kolarov ${ }^{1}$, Daniel Rachev ${ }^{2}$, Desislav \\ Dobrev $^{2}$.
}

1. Department of Oral Surgery, Faculty of Dental medicine, Medical University - Varna;

2. Faculty of Dental medicine, Medical University Varna;

\begin{abstract}
Introduction: The intimate anatomical relationship between the mandibular molars and the mandibular canal may be a precondition for an injury of the inferior alveolar nerve during tooth extraction. Dental imaging has a significant role in avoidance of permanent or temporary neurological complication after extraction of third or second mandibular molars. This study aims to evaluate the relationship between mandibular molars and mandibular canal in a group of patients, regarding the risk of alveolar nerve injury assessed by panoramic radiography.

Materials and methods: For the aim of the study, the distance between the apices of the molars and the superior border of the mandibular canal was measured in 100 patients using panoramic radiographs. According to the relationship the molars were classified into 6 groups.

Results: Three hundred twenty five mandibular molars were observed, but only 94 third molars and 178 second molars were included in the statistics. A total of 36 molars, examined in the panoramic radiographs, are considered to be superimposed on the mandibular canal (Group 1).
\end{abstract}


Conclusion: According to the conducted study, mandibular third molars from Group 1 present 22.34\% of all the examined 94 mandibular third molars. Those molars from Group 1 are most significant for assessing the risk of alveolar nerve injury. The risk of alveolar nerve injury during extraction is significantly higher in third mandibular molars compared to second mandibular molars.

Keywords: third mandibular molars, mandibular canal, panoramic radiography, alveolar nerve.

\section{Introduction}

Extraction of mandibular third molars is a routine surgery, which can be associated with a number of complications including severe pain, alveolitis, an inflammatory process, trismus, iatrogenic injury and alveolar nerve injury. According to a study of Tariq Ahmad and coworkers the frequency of complications are with ranges between $6.7 \%$ and $14.5 \%$ (1). The intimate anatomical relation of the third and second mandibular molars to the mandibular canal leads to a potential risk of alveolar nerve injury during extraction (2,3). According to the International Association for the Study of Pain, the clinical manifestations of nerve injury are anesthesia, hypoesthesia, paraesthesia, dysesthesia, hyperalgesia and allodynia. Paraesthesia of the alveolar nerve injury due to extraction of mandibular third molar is mostly temporary and very rarely permanent. Literature data suggests that the incidence of permanent nerve injury in this case is less than $1 \%(3,4)$.

The medical literature describes various frequencies of the alveolar nerve injury associated with extraction of molars:

1. A study by Gry Karina Kjølle and coworkers mentioned that the frequency of nerve injury, accompanied by postoperative hyperesthesia, paraesthesia, anesthesia or dysesthesiawas $0.9 \%(4)$.

2. C. Alling found that one of 241 patients underwent extraction suffered from alteration of mandibular alveolar nerve, and $3.5 \%$ of the injuries last more than a year (5).

3. In the study of CR Brann and coworkers. 96 of $718(13 \%)$ extracted mandibular third molars are associated with alveolar nerve injury, and only $1 \%$ of the extracted teeth have led to sensory impairment lasting more than 6 months (6).

4. FA Carmichael states that the frequency of alveolar nerve injury with clinical manifestation is $5.5 \%$ in the postoperative period of 6 to 24 hours; $3.9 \%$ - In the period of 7 to 10 days and $0.9 \%$ one year after extraction (7).

5. A study by Tariq Ahmad and coworkers shown that the incidence of this complication from impacted third molars had ranges from $5 \%$ to $7 \%$ of temporary injury and from $0.5 \%$ to $1 \%$ for permanent injury (1).

6. A study by E. Queral-Godoy and coworkers, published in 2005 claimed that the frequency of the alveolar nerve injury as a result of the extraction of the lower third molar is $1.1 \%$ (8).

7. Lagos and coworkers reported that the total incidence of injury in the lower alveolar nerve and lingual nerve, as a result of extraction of impacted third molar, was $13.4 \%$ (9).

8. A study published by J. Gargallo-Albiol and coworkers in 2000 reported that the frequency of temporary injury of the inferior alveolar nerve or lingual nerve ranged from $0.278 \%$ to $13 \%(10)$. 
Radiographic methods of examination are used to determine the anatomical relationship between the mandibular canal (MC) and the roots of the lower molars in order to avoid injury of the mandibular alveolar nerve. The literature states as a method of radiographic reference - the orthopantomography (panoramic radiography, OPG), for which clinicians use a series of radiographic markers for intimate relation of the molars to the $M C(11,12)$.

One of the markers described in the literature, observed on OPG, is the "superimposition", when the lower and upper borders of the mandibular canal are superimposed on the roots of the molars (Figure 1). Other marker is the "increased radiolucency" appeared due to the crossing of the images of the molars with the mandibular canal. In this case both structures are described as darker and more difficult to define zones (Figure 2). Third marker represent disturbance in the top and the bottom border of the mandibular canal in the area of intersection with the root canal $(11,12,13)$.

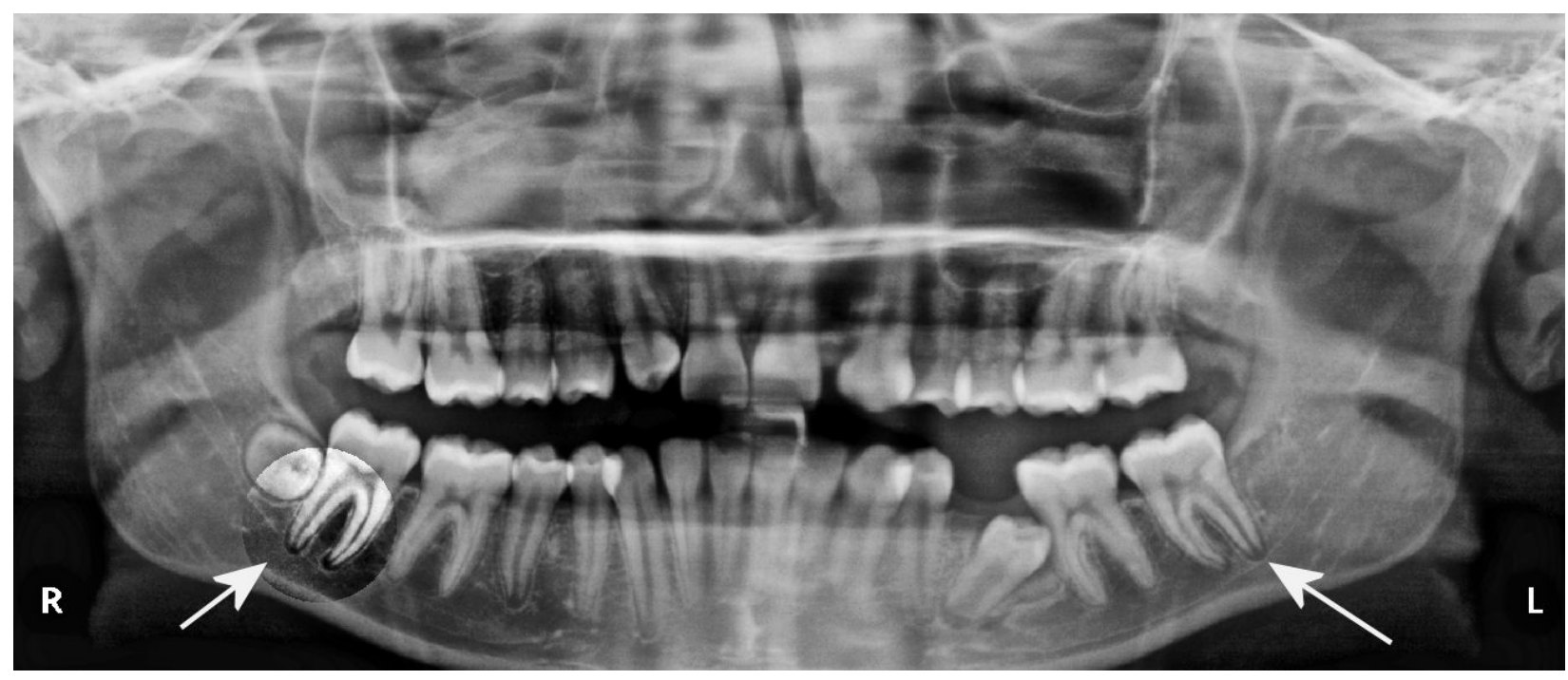

Fig. 1 The borders of the mandibular canal are superimposed on the roots of the second mandibular molars 


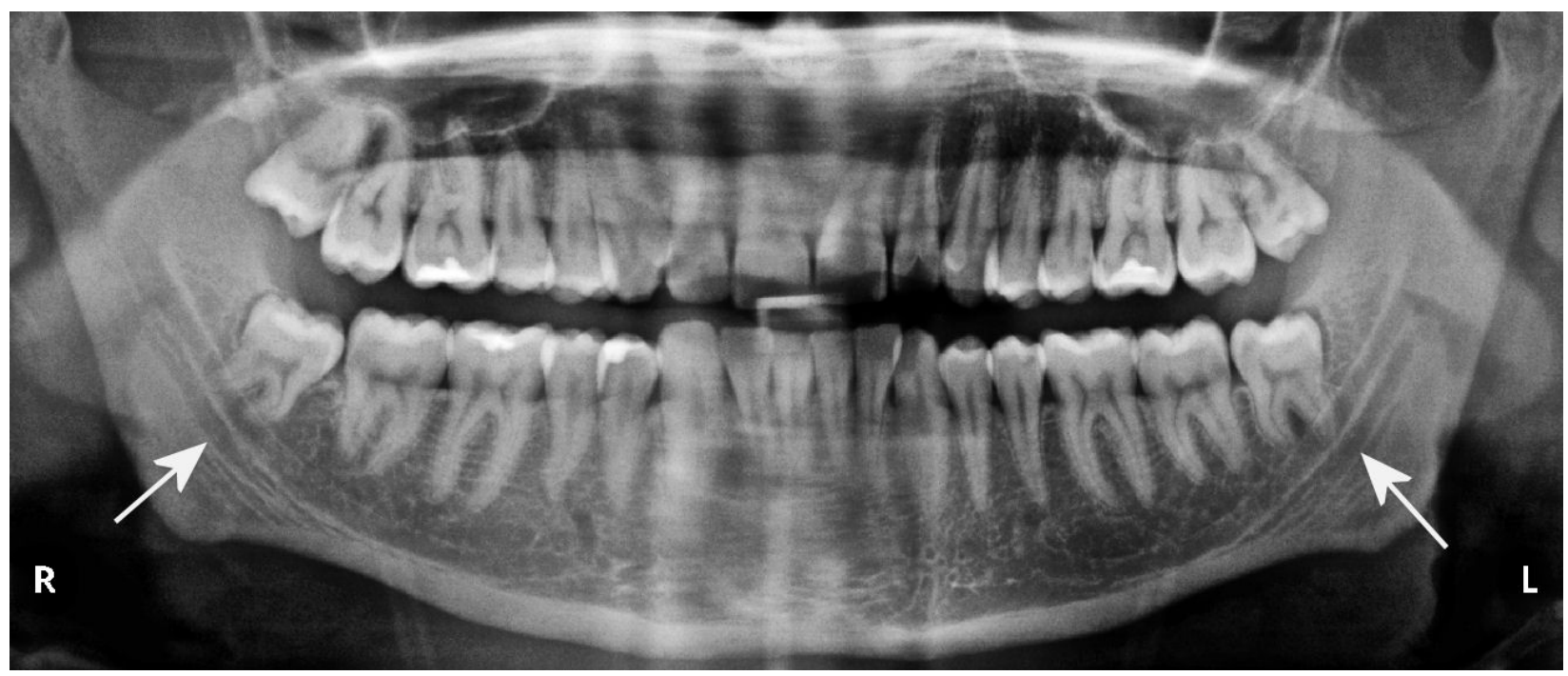

Fig. 2. Increased radiolucency is observable due to the crossing of the images of third mandibular molars with the mandibular canal

According to Giuseppe Monaco and coworkers the predictive value for an intimate relationship between the molars and the MC of these markers is as follows: superimposition - 38.5\%; increased radiolucency $73.0 \%$; disturbance of the upper and lower boundary of the canal $-71.4 \%$ (11).

According to Bart F. Blaeser and coworkers, the presence of one or more of radiographic markers represent $40 \%$ or higher chance of injury of the inferior alveolar nerve during extraction of impacted molars (13).

\section{Aim}

The objectives of this study are:

1. To determine the relation of the mandibular third molars to the mandibular canal.

2. To determine the relation of the second mandibular molars to the mandibular canal.

3. To establish a gender dependency concerning the results of the study.

4. To compare the relationship between third mandibular molars and he mandibular canal with those of the second molars and the canal.

5. To evaluate the advantages and disadvantages of the OPG examination, used for the purpose of the study.

\section{Material and Methods}

For the purpose of this study OPGs of a hundred patients were examined in the Faculty of Dental Medicine, Medical University of Varna "Prof. Dr. Paraskev Stoyanov". The included patients were randomly selected and representatives of male and female gender. A necessary condition for the selection of patients was that the patients must have second and/or third mandibular molars. All of the OPGs were 
selected on the condition to be radiographically clearly visible and identifiable. The distance from the root apex of the mandibular second and third molars to the upper border of the mandibular canal was measured by computer software KODAK Dental Imaging Software 6.12.15.0. The measurement was conducted on penetrated molars with complete root development, Godon's phenomenon molars and impacted molars. Third molars with incomplete root development were not included in the statistics.

The results were classified on the basis of the following classifications:

Classification according to gender: men and women.

Classification of molars according features:

1. Molars with Godon's phenomenon

2. Impacted molars

We suggest a classification of the molars, based on radiographic examination, depending on their relationship with the mandibular canal:

Group 1: The root is projected onto the mandibular canal. This group includes markers predicting the intimate relation of the mandibular canal with molars - superimposition, increased radiolucency and disturbance of the border of the mandibular canal.

Group 2: the distance from the apex to the upper border of the mandibular canal is less than or equal to $0.9 \mathrm{~mm}$.

Group 3: the distance from the apex to the upper border of the mandibular canal is 1 to $1.9 \mathrm{~mm}$.

Group 4: the distance from the apex to the upper border of the mandibular canal is 2 to $2.9 \mathrm{~mm}$.

Group 5: the distance from the apex to the upper border of the mandibular canal is 3 to $3.9 \mathrm{~mm}$.

Group 6: the distance from the apex to the upper border of the mandibular canal is more than $4 \mathrm{~mm}$.

\section{Results}

For the purposes of the study OPGs 53 men and 47 women were examined. The object of the study were 325 mandibular molars, of which 136 are third and 189 - second molars. In the statistical measurement were not included 18 molar in the development stage of follicle or incomplete root development. In 8 molars was not possible to determine their relationship with the mandibular canal. The reason for the failure was unclear delineation of structures as a result of the low quality of the radiographs. The number of examined molars with features is as follows: molars with Godon's phenomenon - 12, impacted third molars -15 . The total number of molars, whose relation to mandibular canal has been identified is 272 (178 - second and 94 - mandibular third molar) of which 36 are in superimposition. 
Table 1. Molars classified by their features.

\begin{tabular}{|c|c|c|c|c|c|c|}
\hline Features of molars & $\begin{array}{l}\text { Lower } \\
\text { second } \\
\text { molar } \\
\text { (right) }\end{array}$ & $\begin{array}{l}\text { Lower } \\
\text { second } \\
\text { molar } \\
\text { (left) }\end{array}$ & $\begin{array}{l}\text { Lower } \\
\text { third } \\
\text { molar } \\
\text { (right) }\end{array}$ & $\begin{array}{l}\text { Lower } \\
\text { third } \\
\text { molar } \\
\text { (left) }\end{array}$ & & \\
\hline Group 1 (superimposition) & 6 & 9 & 8 & 13 & 36 & Total \\
\hline Missing & 2 & 9 & 31 & 33 & 75 & Total \\
\hline Impacted & 0 & 0 & 8 & 7 & 15 & Total \\
\hline Development stage of follicles & 0 & 0 & 5 & 3 & 8 & Total \\
\hline Incomplete root development & 0 & 0 & 5 & 5 & 10 & Total \\
\hline Godon's phenomenon for (F.G.) & 2 & 4 & 3 & 3 & 12 & Total \\
\hline Cannot be determined & 2 & 3 & 2 & 1 & 8 & Total \\
\hline $\begin{array}{l}\text { Total measured teeth }+ \text { group } 1 \\
\text { (without Godon's phenomenon } \\
\text { missing, impacted, follicles, } \\
\text { incomplete root development, } \\
\text { cannot be determined) }\end{array}$ & 94 & 84 & 46 & 48 & 272 & Total \\
\hline $\begin{array}{l}\text { Average of the measured relation } \\
\text { of the molars with the canal }\end{array}$ & $3.4 \mathrm{~mm}$ & $3.0 \mathrm{~mm}$ & $2.6 \mathrm{~mm}$ & $2.3 \mathrm{~mm}$ & $2.8 \mathrm{~mm}$ & Average \\
\hline
\end{tabular}

The average distance from the apex of the molars, which are not superimposed to the mandibular canal is $3.2 \mathrm{~mm}$ for the second molars and $2.5 \mathrm{~mm}$ - for the third molars.

The results of the molars with Godon's phenomenon were separately displayed due to the difference in their relationship to the mandibular canal. Most of them belong to Group 6 (table 1).

15 impacted third molars were reviewed, of which 11 (73.33\%) were projected onto the mandibular canal and belong to Group 1. The results are present on the table 2.

Table 2. Impacted mandibular molars classified into groups according the classification

\begin{tabular}{|l|l|l|}
\hline Group & Molars & Percentage \\
\hline Impacted third molars & 15 & \\
\hline Group1 & 11 & $100 \%$ \\
\hline Group 2 & 2 & $73.33 \%$ \\
\hline Group 3 & 2 & $13.33 \%$ \\
\hline
\end{tabular}

Molars with Godon's phenomenon were located at the farthest distance from the upper border of the mandibular canal, as the average distance is $5.83 \mathrm{~mm}$. The results are present on the table 3 . 
Table 3. The table describes molars with Godon's Phenomenon classified into groups according the classification

\begin{tabular}{|l|l|}
\hline Group & Molars \\
\hline group 6 Godon's phenomenon & 8 \\
\hline group 5 Godon's phenomenon & 3 \\
\hline group 4 Godon's phenomenon & 1 \\
\hline & Millimeters \\
\hline Average distance in Godon's Phenomenon & 5.83 \\
\hline
\end{tabular}

For men the average distance from the apices of the mandibular molars to mandibular canal is respectively $2.66 \mathrm{~mm}$ for the third molars and $-3.54 \mathrm{~mm}$ for the second. In women the results shown distance $2.2 \mathrm{~mm}$ for the third molars and 2.9 - for the second. The number of molars from Group 1 for women is 19 , while for men -17 . The results are present on table 4 .

Table 4. Sexual dependence in the distance measurement of the molars to the mandibular canal

\begin{tabular}{|l|l|l|l|l|l|l|}
\hline & $\begin{array}{l}\text { Lower } \\
\text { second } \\
\text { molar } \\
\text { (right) }\end{array}$ & $\begin{array}{l}\text { Lower } \\
\text { second } \\
\text { molar } \\
\text { (left) }\end{array}$ & $\begin{array}{l}\text { Lower } \\
\text { third } \\
\text { molar } \\
\text { (right) }\end{array}$ & $\begin{array}{l}\text { Lower } \\
\text { third } \\
\text { molar } \\
\text { (left) }\end{array}$ & & \\
\hline $\begin{array}{l}\text { Average for } \\
\text { women } \\
\text { (without } \\
\text { group 1) }\end{array}$ & $3.1 \mathrm{~mm}$ & $2.7 \mathrm{~mm}$ & $2.2 \mathrm{~mm}$ & $2.2 \mathrm{~mm}$ & $2.55 \mathrm{~mm}$ & Average \\
\hline $\begin{array}{l}\text { Average for } \\
\text { men (without } \\
\text { group 1) }\end{array}$ & $3.8 \mathrm{~mm}$ & $3.27 \mathrm{~mm}$ & $2.96 \mathrm{~mm}$ & $2.36 \mathrm{~mm}$ & $3.1 \mathrm{~mm}$ & Average \\
\hline $\begin{array}{l}\text { Group 1 for } \\
\text { women }\end{array}$ & 6 & 6 & 2 & 5 & 19 & Total \\
\hline $\begin{array}{l}\text { Group 1 for } \\
\text { men }\end{array}$ & 0 & 3 & 6 & 8 & 17 & Total \\
\hline
\end{tabular}

The results show that in $36(13.24 \%)$ of 272 molar, their image in OPG is superimposed on the shadow of the mandibular canal. 20 or $7.35 \%$ of the molars are in close proximity to the canal, but the structures do not superimpose.

The total number of the third molars, which belong to Group 1 is 21 or $7.72 \%$, while the number of the second molars of this group is 15 or $5.52 \%$. The results are present on table 5 . 
Table 5. Classification of the molars according the measured relation to the mandibular canal

\begin{tabular}{|c|c|c|c|c|c|c|}
\hline Group & $\begin{array}{l}\text { Lower } \\
\text { second } \\
\text { molar } \\
\text { (right) }\end{array}$ & $\begin{array}{l}\text { Lower } \\
\text { second } \\
\text { molar (left) }\end{array}$ & $\begin{array}{l}\text { Lower } \\
\text { third molar } \\
\text { (right) }\end{array}$ & $\begin{array}{l}\text { Lower } \\
\text { third molar } \\
\text { (left) }\end{array}$ & Total & Total\% \\
\hline $\begin{array}{l}\text { Group } \\
\text { (superimposition) }\end{array}$ & $6(3.37 \%)$ & $9(5.06 \%)$ & $8(8.51 \%)$ & $\begin{array}{l}13 \\
(13.83 \%)\end{array}$ & 36 & $13.24 \%$ \\
\hline Group $2(>0.9)$ & $4(2.25 \%)$ & $4(2.25 \%)$ & $7(7.45 \%)$ & $5(5.32 \%)$ & 20 & $7.35 \%$ \\
\hline Group 3 (1.0 to 1.9 ) & $\begin{array}{l}21 \\
(11.80 \%)\end{array}$ & $\begin{array}{l}23 \\
(12.92 \%)\end{array}$ & $\begin{array}{l}11 \\
(11.70 \%)\end{array}$ & $\begin{array}{l}15 \\
(15.96 \%)\end{array}$ & 70 & $25.84 \%$ \\
\hline Group 4 (2.0 to 2.9 ) & $\begin{array}{l}18 \\
(10.11 \%)\end{array}$ & $15(8.43 \%)$ & $9(9.57 \%)$ & $6(6.38 \%)$ & 48 & $17.65 \%$ \\
\hline Group 5 (3.0 to 3.9 ) & $13(7.30 \%)$ & $13(7.30 \%)$ & $4(4.26 \%)$ & $5(5.32 \%)$ & 35 & $12.87 \%$ \\
\hline Group 6 (> 4.0) & $\begin{array}{l}32 \\
(17.98 \%)\end{array}$ & $\begin{array}{l}20 \\
(11.24 \%)\end{array}$ & $7(7.45 \%)$ & $4(4.26 \%)$ & 63 & $23.16 \%$ \\
\hline
\end{tabular}

\section{Discussion}

One of the most accessible radiographic methods for diagnostic purposes in dentistry is orthopantomography. Koong and coworkers prove in their study that in Australia the majority of Oral and maxillofacial surgeons rely on panoramic radiographs for determining the relation of mandibular third molars with the mandibular canal. However, a relatively small percentage of surgeons considered that data from panoramic radiographs has insignificant accuracy for this purpose (12).

The orthopantomography analysis may bring inaccurate results due to the diversion of the image and its two-dimensional character. $(11,14)$ According to the literature a large percentage of surgeons recommend computer tomography (CT) as the best diagnostic method to determine the relationship of the mandibular molars to the mandibular canal. However, this method is not always used because of its high price and radiation load (14).

It is necessary a further investigation to be conducted in order to obtain the most accurate results, due to the mentioned shortcomings in the methods of this study.

\section{Conclusion}

During the analysis it was found that:

1. $22.34 \%$ of third molars were superimposed on the mandibular canal and belong to Group 1 . $12.77 \%$ are in close proximity to the canal of less than $0.9 \mathrm{~mm}$ (represent in Group 2). $27.66 \%$ belong to Group 3 (with distance range from $1 \mathrm{~mm}$ to $1.9 \mathrm{~mm}$.). In Group 4, 5 and 6 the percent ratio is respectively: $15.95 \%, 9.58 \%$ and $11.71 \%$. Highest percent of the observed third molars in our study belong to Group 3. 
2. 178 second mandibular molars were observed and it was found that the percent ratio in the groups was respectively $8.43 \%$ for Group 1; 4.50\%- Group 2; $24.72 \%$-Group 3; 18.54\%-Group 4; $14.6 \%$-Group 5 and $29.22 \%$ for Group 6 . Highest percent of the observed second molars belong to Group 6.

3. Our study cannot confirm that there is gender dependent predisposition for intimate relationship between the mandibular molars and the mandibular canal, due to the minor differences in the results for both men and women.

4. According to the results third mandibular molars (TMM) are located closer to the mandibular canal. Approximately 2.5 times TMM are more likely to be in Group 1 than the second mandibular molars. Highest percent of the observed third molars belong to Group 3, while most of the second mandibular molars belong to a more distant Group. The risk of IAN injury during extraction of TMM may be greater.

5. OPG is indicated to be the first choice of a method for radiology analysis among majority of doctors only due to its low price and low radiation load. In other hand, diversion of the image and its two-dimensional character are serious disadvantages when accuracy is needed. To accomplish accurate results for the aim of the study further investigation with other radiology methods should be conducted.

\section{References}

1. Ahmad T, -Rahman A, Qureshi Zl et al. Frequency of Nerve Injuries Following Extraction of Impacted Mandibular 3rd Molars. JKCD 2013; 4:1:12-15.

2. Chong BS, Quinn A, Pawar R, et al. The Anatomical Relationship between the Roots of Mandibular Second Molars and the Inferior Alveolar Nerve. International Endodontic Journal 2015; 48:6:549-55. doi:10.1111/iej.12348.

3. Kaushalya K, Eapen B. Peripheral Nerve Damage Following Removal of Mandibular Third Molar: Causes and Prevention. IOSR Journal of Dental and Medical Sciences 2014; 13:1:98102. doi:10.9790/0853-131698102.

4. Kjølle K, Tore B. Low Risk of Neurosensory Dysfunction after Mandibular Third Molar Surgery in Patients Less than 30 Years of Age. A Prospective Study Following Removal of 1220 Mandibular Third Molars. Oral Surgery, Oral Medicine, Oral Pathology and Oral Radiology 2013; 116:4:411-417. doi:10.1016/j.000o.2013.06.024.

5. Alling C. Dysesthesia of the Lingual and Inferior Alveolar Nerves Following Third Molar Surgery. Journal of Oral and Maxillofacial Surgery: Official Journal of the American Association of Oral and Maxillofacial Surgeons 1986;44:6: 454-457.

6. Brann CR, Brickley MR, Shepherd JP. Oral Surgery: Factors Influencing Nerve Damage during Lower Third Molar Surgery. British Dental Journal 1999;10: 514-516. doi:10.1038/sj.bdj.4800155.

7. Carmichael FA., McGowan DA.. Incidence of Nerve Damage Following Third Molar Removal: A West of Scotland Oral Surgery Research Group Study. British Journal of Oral and Maxillofacial Surgery 1992;30:2: 78-82. doi:10.1016/0266-4356(92)90074-S. 
8. Queral-Godoy E, Valmaseda-Castellón E, Berini-AytésL et al. Incidence and Evolution of Inferior Alveolar Nerve Lesions Following Lower Third Molar Extraction. Oral Surgery, Oral Medicine, Oral Pathology, Oral Radiology, and Endodontology 2005;99:3: 259-264. doi:10.1016/j.tripleo.2004.06.001.

9. Lanre A. Do Pathologies Associated with Impacted Lower Third Molars Justify Prophylactic Removal? A Critical Review of the Literature. Oral Surgery, Oral Medicine, Oral Pathology, Oral Radiology, and Endodontology 2006;102:4: 448-452. doi:10.1016/j.tripleo.2005.08.015.

10. Gargallo-Albiol J, Buenechea-Imaz R, Gay-Escoda C. Lingual Nerve Protection during Surgical Removal of Lower Third Molars. A Prospective Randomised Study. International Journal of Oral and Maxillofacial Surgery 2000; 29:4:268-271.

11. Giuseppe M, Montevecchi M, Alessandri Bonetti G et al.Reliability of Panoramic Radiography in Evaluating the Topographic Relationship between the Mandibular Canal and Impacted Third Molars. Journal of the American Dental Association 2004; 312-318.

12. Koong $B$, Pharoah $M$, Bulsara $M$, et al. Methods of Determining the Relationship of the Mandibular Canal and Third Molars: A Survey of Australian Oral and Maxillofacial Surgeons. Australian Dental Journal 2006;51:1: 64-68.

13. Blaeser Bart F,.August M, Bruce Donoff R, et al. Panoramic Radiographic Risk Factors for Inferior Alveolar Nerve Injury after Third Molar Extraction. Journal of Oral and Maxillofacial Surgery 2003;61:4:417-421. doi:10.1053/joms.2003.50088.

14. Gurgel C, Fontenele E, Bezerra T et al. Correlation between Radiographic Signs of Third Molar Proximity with Inferior Alveolar Nerve and Postoperative Occurrence of Neurosensory Disorders: A Prospective, Double-Blind Study. Acta Cirurgica Brasileira 2013;28:3: 221-227. doi:10.1590/S0102-86502013000300011.

\section{Corresponding author:}

Daniel Rachev

Faculty of Dental Medicine, Medical University of Varna 55 Marin Drinov Str.

9002 Varna, Bulgaria

Tel.:+359899864452

e-mail: daniel.rachev@abv.bg 